\title{
Stereochemistry of polymerization by DNA-dependent RNA- polymerase from Escherichia coli: An investigation with a diastereomeric ATP-analogue
}

\author{
(adenosine 5'-O-(1-thiotriphosphate)/uridine 2',3'-cyclic phosphorothioate/ ${ }^{31} \mathrm{P}$-nuclear magnetic resonance)
}

\section{F. ECKSTEIN, V. W. ARMSTRONG, AND H. STERNBACH}

Max-Planck-Institut für experimentelle Medizin, Abteilung Chemie, 34 Göttingen, Hermann-Rein-Straße 3, Germany

Communicated by F. H. Westheimer, April 26, 1976

\begin{abstract}
The phosphodiester bond formation by DNAdependent RNA-polymerase (RNA nucleotidyltransferase, nucleosidetriphosphate:RNA nucleotidyltransferase, EC 2.7.7.6) can in principle result in retention, inversion, or racemization of configuration at the $\alpha$-phosphorus of the nucleoside 5 -triphosphate being polymerized. As a first step in elucidating the stereochemistry of this reaction, one diastereomer $(A)$ of adenosine $5^{\prime}-O$-(1-thiotriphosphate) (ATP $\alpha$ S) was polymerized with UTP in the presence of poly $(\mathrm{dA}-\mathrm{dT})$ poly $(\mathrm{dA}-\mathrm{dT})$. The resulting polymer was enzymatically cleaved to uridine $2^{\prime}, 3^{\prime}$-cyclic phosphorothioate which was determined to be the endo-isomer by comparison with an authentic sample. This shows that no racemization had occurred and that isomer $A$ of $A T P \alpha S$ gives a phosphorothioate diester bond with the $R$-configuration. Whether this represents inversion or retention of configuration awaits elucidation of the absolute configuration of isomer $A$ for ATP $\alpha$ S.
\end{abstract}

Although a large body of literature exists about various aspects of DNA-dependent RNA-polymerases from Escherichia coli and other sources $(1,2)$ little seems to be known about the details of the mechanism of phosphodiester bond formation. An important piece of information pertinent to this mechanism would be to know whether the reaction occurs with retention, inversion, or racemization at the $\alpha$-phosphorus of the nucleoside triphosphate which is added onto the $3^{\prime}-\mathrm{OH}$ group of a growing RNA-chain. We have recently synthesized adenosine $5^{\prime}-O$ (1-thiotriphosphate) (ATP $\alpha \mathrm{S})$, which exists as a pair of diastereomers due to the asymmetry of the $\alpha$-phosphorus caused by the replacement of oxygen by sulfur (Fig. 1) (3). These isomers, whose absolute configuration is not as yet known, have been separated and arbitrarily named A and B. These ATPanalogues are suitable for studying the stereospecificity of the polymerase, as well as the stereochemistry of the enzymatic phosphodiester bond formation. We describe here the polymerization of $A T P \alpha S$, isomer $A$, with UTP and poly $(d A-d T)$ -poly $(\mathrm{dA}-\mathrm{dT})$ to form poly $\left(\mathrm{U}_{\overline{\mathrm{s}}} \mathrm{A}\right)$, its enzymatic hydrolysis to adenylyl $3^{\prime}, 5^{\prime}$-uridine-2', $3^{\prime}$-cyclic phosphorothioate (A-U>pS), and subsequently to adenosine $3^{\prime}$-monophosphate and uridine $2^{\prime}, 3^{\prime}$-cyclic phosphorothioate $(U>p S)$. The assignment of the absolute configuration of the latter by comparison with the authentic diastereomers of $(\mathrm{U}>\mathrm{pS})(4)$ allows us to describe some aspects of the stereochemistry of the polymerization reaction as a first step towards a detailed description of this process.

Abbreviations: ATP $\alpha$, adenosine 5'-O-(1-thiotriphosphate); $\mathrm{U}^{\prime} \mathrm{pS}$, uridine 2', $3^{\prime}$-cyclic phosphorothioate; A-U $>\mathrm{pS}$, adenylyl $3^{\prime}, 5^{\prime}$-uridine-2', $3^{\prime}$-cyclic phosphorothioate; A-UpS, adenylyl $3^{\prime}, 5^{\prime}$-uridine 3 '-phosphorothioate; poly $\left(\mathrm{U}_{\mathrm{3}} \mathrm{A}\right)$, alternating copolymer derived from UTP and adenosine; $5^{\prime}-O$-(1-thiotriphosphate); NMR, nuclear magnetic resonance.,

\section{MATERIALS AND METHODS}

Materials. $E$. coli DNA-dependent RNA-polymerase (RNA nucleotidyltransferase, nucleosidetriphosphate:RNA nucleotidyltransferase, EC 2.7.7.6) (specific activity of 1960 units/mg) was prepared as described (5). Pancreatic RNase (crystalline) and spleen phosphodiesterase (calf spleen, $5 \mathrm{mg} / \mathrm{ml}$, specific activity of 2 units/mg) were obtained from Boehringer, Mannheim, Germany. The diastereomers A and B of ATP $\alpha$ S were synthesized as described (3). $\left[{ }^{14} \mathrm{C}\right] \mathrm{UTP}(1300 \mathrm{dpm} / \mathrm{nmol})$ was a product of Schwarz/Mann (Orangeburg, N.Y.). Poly (dA-dT) -poly(dA-dT) was purchased from Miles Laboratories (Kankakee, Ill.).

Methods. Electrophoresis was carried out in $0.1 \mathrm{M}$ triethylammonium bicarbonate at pH 7.5 on Schleicher and Schüll $2043 \mathrm{~b}$ (washed) paper for $90 \mathrm{~min}$ at $30 \mathrm{~V} / \mathrm{cm}$. ${ }^{31} \mathrm{P}-\mathrm{Nuclear}$ magnetic resonance (NMR) spectra were recorded in $\mathrm{D}_{2} \mathrm{O}$ on a Bruker Physik HFX 60 spectrometer equipped with a Fourier-transform unit (Bruker-Data System B-NC 12) with noise decoupling and with $85 \%$ aqueous $\mathrm{H}_{3} \mathrm{PO}_{4}$ as an external standard. Chemical shifts are expressed in $\delta$-values relative to this standard.

Experimental Procedure. Synthesis of A-U $>$ pS: $\operatorname{Poly}\left(\left[{ }^{14} \mathrm{C}\right] \mathrm{U}_{\overline{\mathrm{s}}} \mathrm{A}\right)$ was prepared from $\mathrm{ATP} \alpha \mathrm{S}$ isomer $\mathrm{A}\left(1500 \mathrm{~A}_{260}\right.$ units, $100 \mu \mathrm{mol})$ and $\left[{ }^{14} \mathrm{C}\right] \mathrm{UTP}(100 \mu \mathrm{mol})$ on poly $(\mathrm{dA}-\mathrm{dT})$ poly $(\mathrm{dA}-\mathrm{dT})$ as described (6). The isolated yield of the polymer was $740 A_{262}$ units $\left(4.9 \times 10^{7} \mathrm{cpm}\right)$. The total amount of polymer was dissolved in $200 \mathrm{ml}$ of $10 \mathrm{mM}$ Tris. $\mathrm{HCl}$ at $\mathrm{pH} \mathrm{7.6}$ and partially hydrolyzed with $8 \mathrm{ml}$ of RNase $(4.8 \mu \mathrm{g} / \mathrm{ml})$. After incubation at $37^{\circ}$ for $1 \mathrm{hr}$ the solution was applied to a DEAE-Sephadex A-25 column $(1 \times 30 \mathrm{~cm})$. No material was eluted with $500 \mathrm{ml}$ of $0.3 \mathrm{M}$ triethylammonium bicarbonate. On subsequent elution with $250 \mathrm{ml}$ of $0.6 \mathrm{M}$ buffer all the material was eluted in a single peak.

Degradation of A-U $>\mathrm{pS}$ : The total amount of the dinucleotide $\mathrm{A}-\mathrm{U}>\mathrm{pS}$ was taken up in $4.5 \mathrm{ml}$ of $\mathrm{H}_{2} \mathrm{O}, 500 \mu \mathrm{l}$ of $1 \mathrm{M}$ acetate-buffer at $\mathrm{pH} 4.9,50 \mu \mathrm{l}$ of EDTA (100 mM, pH 7.4); 100 $\mu \mathrm{l}$ of spleen phosphodiesterase was also added. After $2.5 \mathrm{hr}$ at $37^{\circ}$ another $500 \mu$ l of enzyme was added. After an additional $2.5 \mathrm{hr}$, the solution was chromatographed on a DEAE-Sephadex A-25 column $(1.0 \times 25 \mathrm{~cm})$ with a linear gradient consisting of $500 \mathrm{ml}$ each of $\mathrm{H}_{2} \mathrm{O}$ and $0.3 \mathrm{M}$ triethylammonium bicarbonate. The $\mathrm{U}>\mathrm{pS}$ was eluted with between 0.11 and $0.13 \mathrm{M}$ buffer and adenosine $3^{\prime}$-monophosphate, contaminated with some undegraded dinucleotide, eluted with between 0.15 and $0.20 \mathrm{M}$ buffer. Both fractions were evaporated to dryness and reevaporated with methanol. The residues were dissolved in $2 \mathrm{ml}$ of $\mathrm{H}_{2} \mathrm{O}$. The $\mathrm{U}>\mathrm{pS}$ solution had a total activity of $3.04 \times 10^{7} \mathrm{cpm}$ which corresponded to $62 \%$ of the radioactivity incorporated in the polymer. 
<smiles>O=P([O-])(O)O[P@@](=O)([O-])O[C@H]1O[C@@H]2CC[C@H]1O2</smiles>

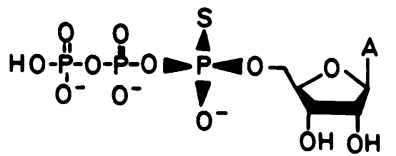

Fig. 1. Structural formulae of diastereomers of ATP $\alpha$ S.

After evaporation to dryness, a ${ }^{31} \mathrm{P}$-NMR spectrum of the $\mathrm{U}>\mathrm{pS}$-fraction was recorded in about $300 \mu \mathrm{l}$ of $\mathrm{D}_{2} \mathrm{O}$. After the spectrum had been recorded, the solution was evaporated to dryness and the residue crystallized from EtOH. The yield was $12.8 \mathrm{mg}\left(\mathrm{mp} 192-200^{\circ}\right)$. The mother liquor contained a total of $5.3 \times 10^{6} \mathrm{cpm}$.

\section{RESULTS}

ATP $\alpha$ S was shown to be a substrate for DNA-dependent RNA-polymerase before the mixture of diastereomers could be resolved (7). To test the stereospecificity of the polymerase, isomers A and B were tested separately in a polymerization assay. As can be seen from Fig. 2, isomer $A$ was a reasonable substrate whereas isomer B was not polymerized. From Lineweaver-Burk plots the following data were derived for ATP $\alpha$ S, isomer A: $K_{m}=0.4 \mathrm{mM}$ and $V_{\max }=0.16 \mathrm{nmol} / \mathrm{min}$. The corresponding values for ATP were $K_{\mathrm{m}}=0.04 \mathrm{mM}$ and $V_{\max }=0.23 \mathrm{nmol} / \mathrm{min}$. Isomer $\mathrm{B}$ of $\mathrm{ATP} \alpha S$ was found to be a competitive inhibitor with $K_{1}=2.8 \mathrm{mM}$. ATP $\alpha \mathrm{S}$, isomer $\mathrm{A}$ is also able to support pyrophosphate exchange (8) into UTP (data not shown) which indicates that it can also enter the initiation site of the enzyme. However, the concentrations required for this reaction are higher than with ATP and are similar to those

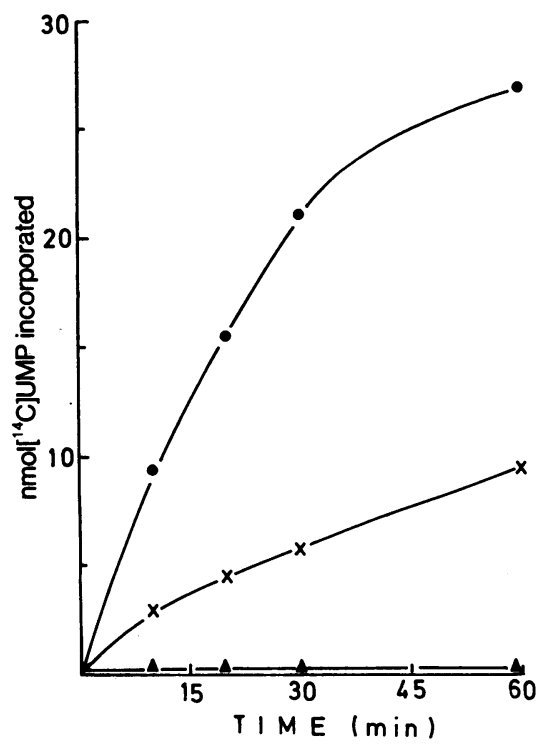

FIG. 2. Polymerization of ATP $\alpha$ S and ATP. The assay solution $(0.25 \mathrm{ml})$ contained $40 \mathrm{mM}$ Tris $\cdot \mathrm{HCl}$ at $\mathrm{pH} 8.0,8 \mathrm{mM} \mathrm{MgCl}, 0.2 \mathrm{M}$ $\mathrm{KCl}, 10 \mathrm{mM}$ dithioerythritol, $0.2 A_{260}$ units of poly(dA-dT) $\cdot$ poly(dA-dT), $26 \mu \mathrm{g}$ of enzyme, $1 \mathrm{mM}\left[{ }^{14} \mathrm{C}\right] \mathrm{UTP}$ and $1 \mathrm{mM}$ of ATP

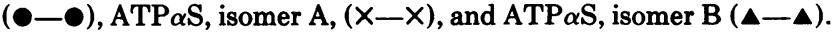
The solutions were incubated at $37^{\circ}, 50 \mu$ laliquots were removed after the times indicated, and the acid-precipitable radioactivity determined on Whatman $3 \mathrm{MM}$ filter discs.
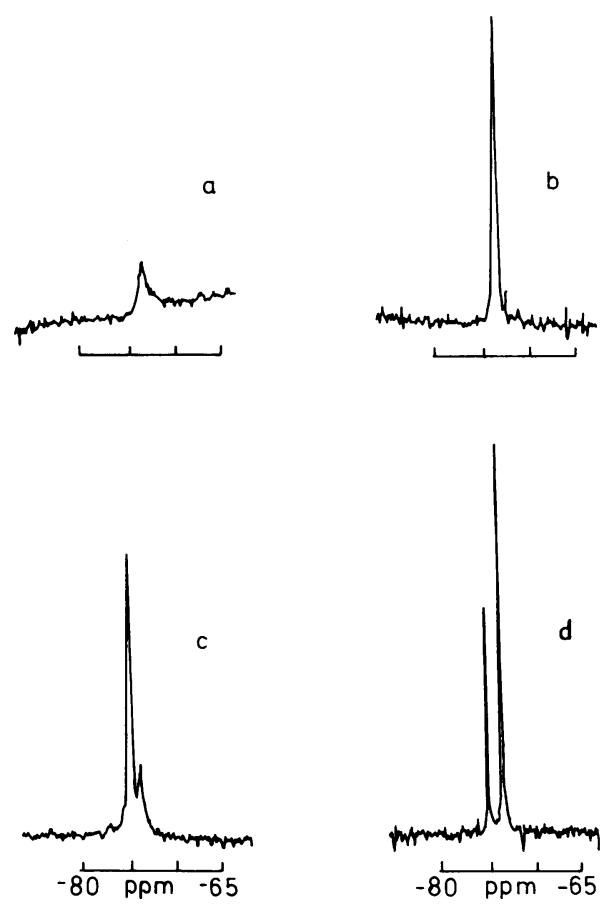

Fig. 3. ${ }^{31} \mathrm{P}-\mathrm{NMR}$ spectra. (a) A-U>pS; $\delta=-73.62 \mathrm{ppm}$. (b) $\mathrm{U}>\mathrm{pS}$ isolated from poly $\left(\mathrm{U}_{\mathrm{3}} \mathrm{A}\right) ; \delta=-73.89 \mathrm{ppm}$. (c) $\mathrm{U}>\mathrm{pS}$, authentic exo-isomer $(\delta=-75.57 \mathrm{ppm})$ contaminated by some endo-isomer $(\delta$ $=-74.13 \mathrm{ppm}$ ). (d) mixture of crystalline $\mathrm{U}>\mathrm{pS}$ isolated from poly $\left(\mathrm{U}_{3} \mathrm{~A}\right)$ and authentic exo-isomer $(\delta=-74.67 \mathrm{ppm}$ and -76.05 ppm).

observed with ADP. In contrast, $\mathrm{ATP} \alpha \mathrm{S}$, isomer B shows very little exchange.

In the large scale polymerization of $\mathrm{ATP} \alpha \mathrm{S}$ (isomer A) and $\left[{ }^{14} \mathrm{C}\right] \mathrm{UTP}$, about $50 \%$ of the substrates were incorporated into the polymer. Partial digestion of the polymer with RNase yielded only one product as shown by electrophoresis (electrophoretic mobility was $10 \mathrm{~cm}$ ). That this was A-U>pS could be shown by comparison with a small sample of $A-U>p S(0.25$ $A_{260}$ units) which had been treated with a large amount of RNase $(10 \mu \mathrm{l}, 4.8 \mathrm{mg} / \mathrm{ml})$ in $50 \mu \mathrm{l} 0.1 \mathrm{M} \mathrm{Tris} \cdot \mathrm{HCl}$ at $\mathrm{pH} 7.6$ for $1 \mathrm{hr}$ at $37^{\circ}$ to hydrolyze the cyclic phosphorothioate to adenylyl $3^{\prime}, 5^{\prime}$-uridine $3^{\prime}$-phosphorothioate (A-UpS). As expected, this product had a higher electrophoretic mobility $(16 \mathrm{~cm})$ than $\mathrm{A}-\mathrm{U}>\mathrm{pS}$ at $\mathrm{pH}$ 7.6. The ${ }^{31} \mathrm{P}-\mathrm{NMR}$ spectrum shows only the expected signals for a phosphate diester (approximately 1.0 ppm, not shown) $(9,10)$ and a cyclic phosphorothioate (approximately $-74 \mathrm{ppm}$ ) (Fig. 3). The hydrolysis of $\mathrm{A}-\mathrm{U}>\mathrm{pS}$ with spleen phosphodiesterase went to about $95 \%$ completion as judged from the reisolated starting material. The ${ }^{31} \mathrm{P}-\mathrm{NMR}$ spectrum of the isolated $U>\mathrm{pS}$ (electrophoretic mobility $14 \mathrm{~cm}$ ) (Fig. 3) shows only one signal at $-73.89 \mathrm{ppm}$. This material crystallized and had practically the same melting point as that of an authentic sample of the endo-isomer of $U>p S(4,11)$. The NMR-spectrum of a solution containing the isolated crystalline material and authentic exo-isomer showed two signals for the two isomers (Fig. 3d).

\section{DISCUSSION}

DNA-dependent RNA-polymerase catalyzes the formation of a phosphodiester bond between the $3^{\prime}-\mathrm{OH}$ group of a growing RNA-chain and the $\alpha$-phosphorus of a nucleoside 5'-triphosphate with release of pyrophosphate. The mechanistic, particularly the stereochemical, details of this process are poorly understood. However, for a complete understanding of the 
enzyme mechanism such information is essential. Several alternative mechanisms for the formation of the phosphodiester bond can be envisaged: (i) nucleophilic substitution of pyrophosphate at the $\alpha$-phosphorus of the nucleoside $5^{\prime}$-triphosphate by the $3^{\prime}-\mathrm{OH}$ group of the growing RNA-chain with inversion of configuration at phosphorus, (ii) formation of an enzymenucleoside 5 '-phosphate intermediate by nucleophilic substitution of pyrophosphate with a nucleophilic group of the enzyme and subsequent reaction of this intermediate and the growing polymer with overall retention of configuration of the $\alpha$-phosphorus. These reactions could proceed by way of a pentacoordinated phosphorus intermediate which has the form of a trigonal bipyramid either through an in-line mechanism (12) where the incoming nucleophile ( $3^{\prime}-\mathrm{OH}$ group) as well as the leaving group (pyrophosphate) both occupy apical positions (leading to inversion) or an adjacent mechanism where the nucleophile is in an apical and the leaving group in an equatorial position (Fig. 4). In this latter case, the trigonal bipyramid has to undergo a pseudorotation to position the leaving group in an apical position for expulsion and this would lead to retention of configuration. Although this concept was first applied to the hydrolysis of five-membered cyclic phosphates (13), it does not need to be limited to such cases. As discussed in detail (14), various alternatives can be envisioned by which the interaction of enzyme and substrate results in imposing the constraints of a pentacoordinate phosphorus onto a noncyclic substrate. To decide between these mechanisms it would be helpful to know whether inversion, retention, or racemization of configuration occurs at the $\alpha$-phosphorus.

It has been shown that nucleoside phosphorothioates are suitable compounds for such studies. Thus, the stereochemical course of both steps of pancreatic RNase has been determined (15-17) by use of uridine 2', $3^{\prime}$-cyclic phosphorothioate. For a similar study of RNA-polymerase, a nucleoside 5 '-triphosphate is needed which has a phosphorothioate instead of a phosphate group in the $\alpha$-position. Such a compound is adenosine $5^{\prime}-O$ (1-thiotriphosphate) whose separated diastereomers have recently become available (3). However, it is not enough that the starting material is stereochemically pure, but also that the stereochemistry of the product can be determined. As yet there is no way in which the two diastereomers of a phosphorothioate internucleotidic linkage can be separated, and so another approach must be used. By employing poly $(\mathrm{dA}-\mathrm{dT}) \cdot \mathrm{poly}(\mathrm{dA}-\mathrm{dT})$ as template with ATP $\alpha$ and UTP as substrates, one obtains a polymer poly $\left(U_{\bar{s}} A\right)$ in which the internucleotidic linkage between the $3^{\prime}$-position of $U$ and the $5^{\prime}$-position of $A$ is a phosphorothioate. The stereochemical course of transesterification of such a linkage by limited digestion with pancreatic RNase is known from the studies of this enzyme with $U>p S(16,17)$. The diastereomers of the new compound $A-U>p S$ can be analyzed by ${ }^{31} \mathrm{P}-\mathrm{NMR}$, the cyclic phosphorothioate signals being separated by $\mathrm{ca} 1 \mathrm{ppm}$ in $\mathrm{U}>\mathrm{pS}$. By comparing the ${ }^{3 \mathrm{~T}} \mathrm{P}-\mathrm{NMR}$ spectrum of $\mathrm{A}-\mathrm{U}>\mathrm{pS}$ with that of the two diastereomers of $\mathrm{U}>\mathrm{pS}$ (Fig. 3) one can see that only one diastereomer ( -73.86 ppm) has been formed. This chemical shift is close to that of the endo-isomer of $\mathrm{U}>\mathrm{pS}(-74.13 \mathrm{ppm})$ and different to that of the exo-isomer of $\mathrm{U}>\mathrm{pS}(-75.57 \mathrm{ppm})$.

Although it has not been shown that the presence of $3^{\prime}$ AMP in the $5^{\prime}$-position of $U>\mathrm{pS}$ does not change the chemical shift of the phosphorothioate signal, this seems to be a reasonable assumption particularly since substitution of uracil by guanime in the $\mathrm{l}^{\prime}$-position does not alter the chemical shift of the cyclic phosphorothioate (18). To confirm this, we hydrolyzed A-U $>$ pS with spleen phosphodiesterase and analyzed the $U>p S$ after isolation by ion-exchange chromatography. The chemical shift
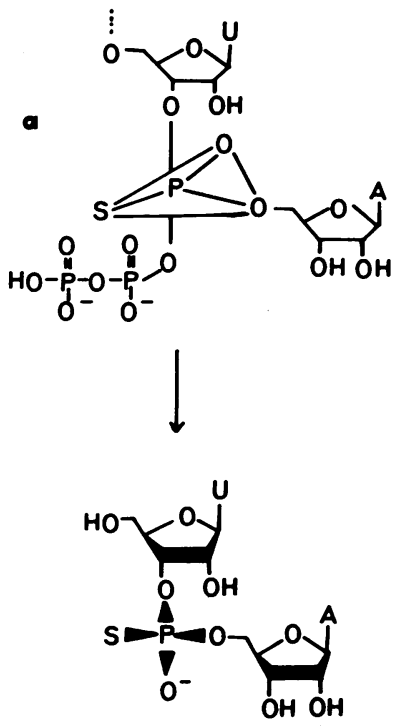

INVER S10 N
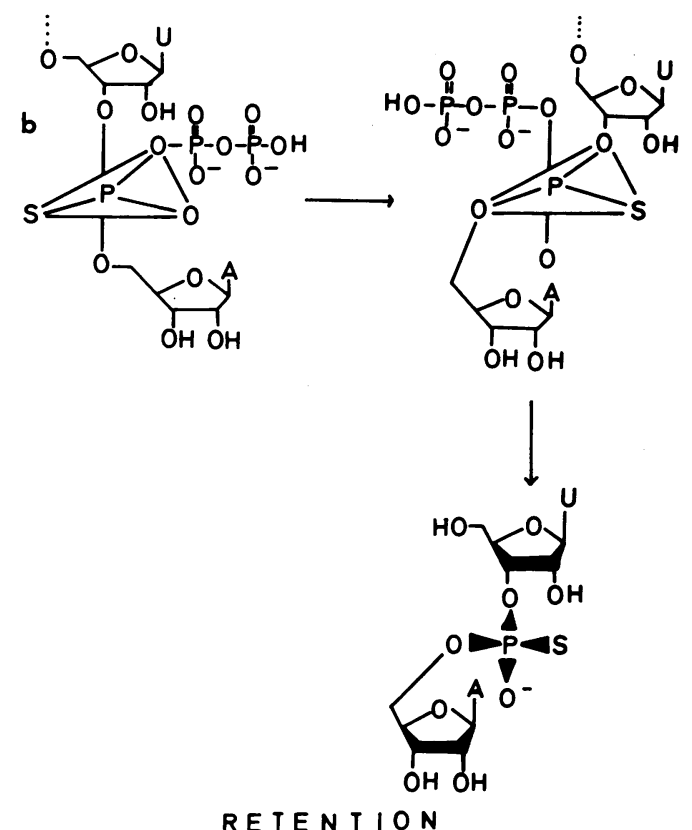

FIG. 4. Alternatives for phosphodiester bond formation involving pentacoordinate phosphorus. Addition of $\mathrm{ATP} \alpha \mathrm{S}$ to a RNA-chain terminating with uridine. (a) In-line. (b) Adjacent.

observed for $U>p S$ was identical to that of $A-U>p S$. To eliminate any uncertainty in the assignment of the signal we crystallized the $\mathrm{U}>\mathrm{pS}$ obtained by spleen phosphodiesterase digestion. This material had the same melting point as the endo-isomer synthesized by chemical methods. The exo-isomer has to our knowledge not been obtained in a crystalline form. Final confirmation that this was indeed the endo-isomer was obtained from a NMR-spectrum of a mixture of authentic exo-isomer and the crystalline product. In this case two signals were obtained (Fig. 3d). The diastereomer in A-U $>$ pS is thus the endo-isomer.

The transesterification step of pancreatic RNase proceeds by an in-line mechanism as has been determined with the methyl ester of uridine $3^{\prime}$-phosphorothioate (17) as well as by the reaction of $U>p S$ with cytidine (16). If the transesterification of poly $\left(U_{\bar{s}} A\right)$ proceeds by the same mechanism, and there 


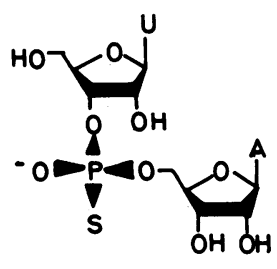

$\mathbf{S}$

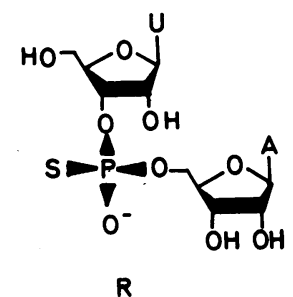

$\mathbf{R}$

FiG. 5. $S$ and $R$ configurations of phosphorothioate group.

is no reason to suppose that it does not, then the endo-isomer of $A-U>p S$ must be the result of transesterification of the polymer with the $R$-configuration of the phosphorothioate group (Fig. 5).

These experiments show that the polymerization of ATP $\alpha S$, isomer A, by DNA-dependent RNA-polymerase produces a phosphorothioate linkage with the $\boldsymbol{R}$-configuration. Because there is no sign of a signal which corresponds to the exo-isomer of $\mathrm{U}>\mathrm{pS}$, no racemization has taken place during the polymerization reaction. To determine whether this reaction has occurred with retention or inversion of configuration, the absolute configuration of $\mathrm{ATP} \alpha \mathrm{S}$ (isomer A) has to be known. This, however, is not the case at present. We therefore consider our results as a first step in elucidating the stereochemistry of the polymerization.

This sort of study is not restricted to DNA-dependent RNA-polymerase from $E$. coli but can be extended to any RNA-polymerase. It might even be possible to investigate DNA-dependent DNA-polymerases by this approach because it is known that under certain conditions at least the $E$. coli enzyme also accepts ribonucleoside $5^{\prime}$-triphosphate as substrates (19). At present we are engaged in similar experiments with

tRNA-nucleotidyl transferase which also accepts ATP $\alpha$, isomer $A$, as a substrate.

We thank B. Seeger for recording the NMR-spectra and the Deutsche Forschungsgemeinschaft for financial support.

1. Chamberlin, M. J. (1974) Annu. Rev. Biochem. 43, 721-775.

2. Chamberlin, M. J. (1974) Enzymes 10, 333-374.

3. Eckstein, F. \& Goody, R. S. (1976) Biochemistry 15, 16851691.

4. Saenger, W. \& Eckstein, F. (1970) J. Am. Chem. Soc. 92, 4712-4718.

5. Sternbach, H., Engelhardt, R. \& Lezius, A. G. (1975) Eur. J. Biochem. 60, 51-55.

6. Eckstein, F. \& Scheit, K. H. (1971) in Procedures in Nucleic Acid Research, eds. Cantoni, G. L. \& Davies, D. R. (Harper and Row, New York), Vol. II, pp. 665-679.

7. Gindl, H. \& Eckstein, F. (1970) Eur. J. Biochem. 13, 558-564.

8. Krakow, J. S. \& Fronk, E. (1969) J. Biol. Chem. 244, 59885993.

9. Mandel, M. \& Westley, J. W. (1964) Nature 203, 301-302.

10. Tsuboi, M., Takahashi, S., Kyogoku, Y., Hayatsu, H., Ukita, T. \& Kainosho, M. (1969) Science 166, 1504-1506.

11. Eckstein, F. (1968) FEBS Lett. 2, 85-86.

12. Usher, D. A. (1969) Proc. Natl. Acad. Sci. USA 62, 661-667.

13. Westheimer, F. H. (1968) Acc. Chem. Res. 1, 70-78.

14. Benkovic, S. J. \& Schray, K. J. (1973) Enzymes 8, 201-238.

15. Usher, D. A., Richardson, D. J., Jr. \& Eckstein, F. (1970) Nature 228, 663-665.

16. Usher, D. A., Erenrich, E. S. \& Eckstein, F. (1972) Proc. Natl. Acad. Sci. USA 69, 115-118.

17. Saenger, W., Suck, D. \& Eckstein, F. (1974) Eur. J. Biochem. 46, 559-567.

18. Eckstein, F., Schulz, H. H., Rüterjans, H., Haar, W. \& Maurer, W. (1972) Biochemistry 11, 3507-3512.

19. Van de Sande, J. H., Loewen, P. C. \& Khorana, H. G. (1972) J. Biol. Chem. 247, 6140-6148. 